\title{
Increased expression of FAK isoforms as potential cancer biomarkers in ovarian cancer
}

\author{
MANUEL NOLASCO-QUIROGA ${ }^{1}$, MARISOL ROSAS-DÍAZ ${ }^{2}$, JOSÉ MORENO ${ }^{3}$, \\ RICARDO GODÍNEZ-AGUILAR ${ }^{3}$, MARÍA JOSÉ LÓPEZ-IBARRA ${ }^{1}$, PATRICIA PIÑA-SÁNCHEZ ${ }^{4}$, \\ ISABEL ALVARADO-CABRERO ${ }^{5}$, GERARDO VÁZQUEZ-GÓMEZ ${ }^{6}$, LETICIA ROCHA-ZAVALETA ${ }^{7}$, \\ DIEGO ARENAS-ARANDA ${ }^{1 *}$ and FABIO SALAMANCA-GÓMEZ ${ }^{1,8}$
}

\begin{abstract}
${ }^{1}$ Laboratory of Molecular Genetics, Medical Research Unit, Mexican Social Security Institute, National Medical Center Century XXI, Hospital of Pediatrics, Mexico City 06720; ${ }^{2}$ Multidisciplinary Academic Unit Reynosa-Aztlan Reynosa, Autonomous University of Tamaulipas, Tamaulipas $88740 ;{ }^{3}$ Direction of Research, Hospital Juárez de México, Mexico City 07760; ${ }^{4}$ Medical Research Unit of Oncologic Diseases; ${ }^{5}$ Department of Anatomy-Pathology, Mexican Social Security Institute, National Medical Center Century XXI, Oncology Hospital, Mexico City 06720; Departments of ${ }^{6} \mathrm{Genomic}$ Medicine and Envornmental Toxicology, and ${ }^{7}$ Molecular Biology and Biotechnology, National University of Mexico; ${ }^{8}$ Medical Research Coordination, Mexican Social Security Institute, National Medical Center Century XXI, Mexico City 04510, Mexico
\end{abstract}

Received July 21, 2017; Accepted December 7, 2018

DOI: $10.3892 /$ ol.2019.10147

\begin{abstract}
Focal adhesion kinase (FAK) is a non-receptor tyrosine kinase that is expressed in most human cell types (example: Epithelial cells, fibroblasts and endothelial), it serves a key role in the control of cell survival, proliferation and motility. The abnormal expression of FAK has been associated with poor prognosis in cancer, including ovarian cancer. However, although FAK isoforms with specific molecular and functional properties have been characterized, there are a limited number of published studies that examine FAK isoforms in ovarian cancer. The aim of the present study was to analyze the expression level of FAK and its isoforms in ovarian cancer. The expression of FAK kinase and focal adhesion targeting (FAT) domains was determined with immunohistochemistry in healthy ovary, and serous and mucinous cystadenoma, borderline tumor and carcinoma samples. Additionally, the expression of FAK and its isoforms were investigated in three ovarian cancer-derived cell lines with western blotting and reverse transcription-semi-quantitative polymerase chain reaction. An increased expression of FAK kinase domain was determined in serous tumor samples and was associated with advancement of the lesion. FAK kinase domain expression was
\end{abstract}

Correspondence to: Dr Fabio Salamanca Gómez, Medical Research Coordination, Mexican Social Security Institute, National Medical Center Century XXI, 330 Avenue Cuauhtemoc, Mexico City 04510, Mexico

E-mail: fabio.salamanca@imss.gob.mx

"Deceased

Key words: isoforms, focal adhesion kinase, biomarkers, ovarian cancer, mucinous, serous moderate-to-low in mucinous tumor samples. The expression of the FAK FAT domain in tumor samples was reduced, compared with healthy ovary samples; however, the FAT domain was localized to the cellular nucleus. Expression of alternative transcripts $\mathrm{FAK}^{0}, \mathrm{FAK}^{28,6}$ and $\mathrm{FAK}^{28}$ was determined in all three cell lines investigated. In conclusion, FAK kinase and FAT domains are differentially expressed among ovarian tumor types. These results indicated the presence of at least two isoforms of FAK (FAK and the putative FAK-related non-kinase) in tumor tissue, which is supported by the cells producing at least three FAK alternative transcripts. These results may support the use of FAK and its isoforms as biomarkers for ovarian cancer.

\section{Introduction}

In 2012 ovarian cancer (OCa) is the second most prevalent type of gynecological cancer globally $(1,2)$. Due to OCa being asymptomatic during early stages, the majority of patients are diagnosed in advanced stages, resulting in a notably poor survival rate $(3,4)$. Ovarian tumors are classified into benign, cystadenoma, borderline and malignant lesions (5). A total of $\sim 70-80 \%$ of OCa cases are epithelial in origin, and the most common histological type is serous carcinoma (6). The most frequent subtypes are endometrial, clear cells, mucinous and undifferentiated carcinomas $(5,7)$. Currently, only two biomarkers [cancer antigen (CA)125 and CA119] are used for the clinical diagnosis of OCa (8); however, these markers are not increased in all patients with $\mathrm{OCa}$, and they can also be elevated in other cancer types $(8,9)$. Therefore, their decreased sensitivity and specificity limit the merit of these biomarkers as screening tools and increase the requirement for novel diagnostic and prognostic markers.

Focal adhesion kinase (FAK), a non-receptor tyrosine kinase that serves a key role in the integration of signals from activated membrane receptors, the majority of which are 
within the integrin family (10), has been proposed as a potential marker of OCa (11-13). FAK is expressed in a wide range of human tissue and cell types, and it has been associated with the control of survival, proliferation and motility via integrin-dependent adhesion and signaling pathways $(10,14)$. FAK consists of the following three domains: An amino-terminal band 4.1, ezrin, radixin, moesin (FERM) domain; a central kinase domain; and a C-terminal focal adhesion targeting (FAT) domain (15). The FERM domain is a non-catalytic motif that binds a number of growth factor receptors, including epidermal growth factor receptor, platelet derived growth factor receptor and vascular endothelial growth factor receptor 2. FAK possesses a nuclear localization sequence and it is able to interact with nuclear proteins, including p53 (16). The kinase domain phosphorylates downstream substrates to convey cellular signals from the aforementioned receptors. The FAT domain contains two proline-rich sequences and is required for localization at the focal adhesions (17).

There are multiple isoforms of FAK, with multiple FAK transcripts resulting from alternative splicing and/or promoters. Schaller et al (18) identified a truncated isoform of FAK lacking the kinase domain. This truncated isoform is known as FAK-related non-kinase (FRNK) and functions as a dominant negative regulator of FAK (18). The standard transcript of FAK, lacking exons 13, 14, 16 and 31, is termed FAK ${ }^{0}$. Additional FAK isoforms include $\mathrm{FAK}^{+}$, which contains a three-amino acid insertion in the FAT sequence of exon 31 . FAK ${ }^{6}$ contains six additional residues inserted following residue 392 (exon 14). $\mathrm{FAK}^{7}$ contains seven additional residues in exon 16 . $\mathrm{FAK}^{+6,7}$ contains all insertions from the former three isoforms. Finally, $\mathrm{FAK}^{+6,7,28}$ (exons 13, 14 and 16), which contains 28 additional residues in the vicinity of box $6(19,20)$. FAK variants are differentially expressed in various tissues at different stages of maturation and appear to differ in their phosphorylation ability (21).

Alternative splicing also alters the autophosphorylation rate of FAK, with $\mathrm{FAK}^{+}$and $\mathrm{FAK}^{0}$ having a low autophosphorylation capacity, while $\mathrm{FAK}^{+6,7}$ and $\mathrm{FAK}^{+6,7,28}$ display increased autophosphorylation (19). A number of studies have associated FAK with oncological diseases. Additionally, Despeaux et al (22) determined that $\mathrm{FAK}^{6}, \mathrm{FAK}^{6,7}$ and $\mathrm{FAK}^{6,28}$ are expressed by myeloid leukemia cells and are associated with increased mortality rate of patients.

Increased expression of FAK has been detected in ovarian carcinomas and is associated with a poor prognosis $(13,23)$. Increased levels of the active form of FAK have also been associated with the aggressiveness of the tumor (24). However, to the best of our knowledge, a comprehensive study of the expression of FAK throughout the development of different histological types of ovarian tumor has not been conducted to date; therefore, the aim of the present study was to investigate the FAK expression level in serous and mucinous cystadenoma, borderline tumor and carcinoma samples, along with healthy ovary samples. Additionally, the expression of FAK ${ }^{0}, \mathrm{FAK}^{28}$ and $\mathrm{FAK}^{28,6}$ isoforms was determined in human OCa-derived cell lines.

\section{Materials and methods}

Tissue samples. A total of 161 archival, paraffin-embedded ovarian tissue samples were obtained in 2015 from the
Pathological Oncology Service of the Century XXI National Medical Center (CMN-SXXI), the General Hospital of Mexico and the Hospital of Gynaecology and Obstetrics No. 4 IMSS (Mexico City, Mexico), under approval of the Committee of Ethics of each hospital. The samples were obtained from patients treated in the aforementioned hospitals between January 2010 and December 2013, the samples were from postmenopausal patients prior to treatment and with definitive diagnosis of ovarian cancer. Slides $(5-\mu \mathrm{m})$ were obtained, the slides were deparaffinized in an oven at $60^{\circ} \mathrm{C}$ for $20 \mathrm{~min}$, then incubated in xylene at room temperature for $15 \mathrm{~min}$, and a graded series of ethanol (100, 70 and 30\%) for $5 \mathrm{~min}$ and rinsed in $\mathrm{H}_{2} \mathrm{O}$. All slides were incubated with hematoxylin for $1 \mathrm{~min}$ at room temperature, subsequently slides were then washed with PBS solution and finally were incubated with eosin for $30 \mathrm{sec}$ and evaluated with an optical microscope at x20 magnification by an experienced pathologist. Upon histopathological examination, the samples were classified as follows: 50 serous carcinoma samples; 25 serous borderline tumor samples; 25 serous cystadenoma samples; 6 mucinous carcinoma samples; 14 mucinous borderline tumor samples; 25 mucinous cystadenoma samples; and 16 healthy ovary samples. Additionally, archival, paraffin-embedded 25 tumor samples ( 5 cervical cancer, 10 breast cancer, 5 colon cancer and 5 prostate cancer) positive for the expression of FAK, were obtained from the Pathological Oncology Service of the CMN-SXXI in 2015, were from patients (men and women) with a definitive diagnosis of cancer, prior to treatment and without an age range and were included as positive controls. These patients were treated at the CMN-SXXI between 2010 and 2013.

Immunohistochemistry for the analysis of FAK expression. Areas containing tumor tissue were identified in H\&E-stained slides from each paraffin-embedded sample. These samples were assembled into a multi-tissue block, according to the methodology reported by Hidalgo et al (25). Slices $(5 \mu \mathrm{m})$ were cut from the multi-tissue block, placed on glass slides, deparaffinized using xylene in an oven at $60^{\circ} \mathrm{C}$ for $20 \mathrm{~min}$, and then rehydrated in graded concentrations of ethanol $(100,70$ and $30 \%)$ and rinsed in $\mathrm{H}_{2} \mathrm{O}$. The slides were incubated in citrate buffer (Biocare Decloaker DIVA; Biocare Medical, LLC, Paheco, CA, USA) at $90^{\circ} \mathrm{C}$ for $10 \mathrm{~min}$ for antigen retrieval, and were then washed with PBS solution. The Mouse/Rabbit Immunodetector HRB/DAB Detection kit (Bio, Sb, 0003LH Santa Barbara, CA, USA) was used for the visualization of the antibody, endogenous peroxidase was inhibited by incubation with Peroxide Immunodetector Blocker (Bio, Sb, 0003LH Santa Barbara) at room temperature for $15 \mathrm{~min}$. Following washing with PBS, the slides were incubated with anti-FAK kinase domain (dilution 1:200, cat. no. GTX50666; GeneTex, Inc., Irvine, CA, USA) and anti-FAT domain (dilution 1:200, cat. no. GTX50489; GeneTex Inc.) primary antibodies for $24 \mathrm{~h}$ at $4^{\circ} \mathrm{C}$. Following washing with PBS, tissues were incubated with Biotin Immunodetector (Bio, Sb, 0003LH) at room temperature for $20 \mathrm{~min}$, followed by incubation with Label Immunodetector (Bio, Sb, 0003LH Santa Barbara, CA, USA). To detect the reaction, slides were incubated with an Immunodetector DAB Chromogen kit (Bio, Sb, 0003LH Santa Barbara, CA, USA), and then counterstained 
with haematoxylin and mounted with resin, according to the manufacturer's protocol. Each sample was studied in assays conducted in triplicate.

Semi-quantitative analysis of the reaction was performed under an optical microscope at 20x magnification, according to the system described by Allred et al (26), which considers two criteria: The number of positive cells; and the intensity of the reaction. Visual analysis was conducted by three independent observers. A sample was considered negative when $<5 \%$ cells exhibited immunostaining. Samples with low reaction intensity and $6-25 \%$ positive cells were considered low positive (+), samples with moderate intensity of reaction and $26-75 \%$ positive cells were considered intermediate positive $(++)$, and samples with high-intensity reaction and $>76 \%$ cells exhibiting immunoreaction were considered highly positive $(+++)$. For densitometric analysis, three microphotographs were captured of each sample with an Olympus BX40 optical microscope at 20x magnification. The samples were analyzed using Image-Pro Plus ver. 5.0 software (Media Cybernetics, Inc., Rockville, MD, USA).

Cell lines. Cell lines SKOV3 and NIH-OVCAR3 were donated by Dr. Fabián Arechavaleta-Velasco and Dr. Laura Díaz-Cueto (Hospital of Gynecology and Obstetrics No. 4 IMSS, Mexico City, Mexico). TOV-112D and HeLa cell lines were purchased from American Type Culture Collection (Manassas, VA, USA). The human ovary cancer cell line SKOV3 was derived from the ascites fluid of a 64-year-old Caucasian female with an invasive ovarian adenocarcinoma (27). The SKOV3 cell line exhibits epithelial and adherent morphology. The NIH-OVCAR3 was derived from malignant ascites fluid from a patient with progressive ovarian adenocarcinoma and grown as a cobblestone-like monolayer with multilayered foci (28). The TOV-112D cell line was derived from a primary malignant ovarian adenocarcinoma grade 3 , stage III (29). The human cervical cancer-derived HeLa cell line was included as a positive control for the expression of FAK (30). The SKOV3, NIH-OVCAR3, TOV-112D and HeLa cell lines were cultured in Dulbecco's modified Eagle's medium (Invitrogen; Thermo Fisher Scientific, Inc., Waltham, MA, USA) supplemented with $10 \%$ fetal bovine serum (Invitrogen; Thermo Fisher Scientific, Inc.) and $0.1 \mathrm{mg} / \mathrm{ml}$ streptomycin.

Western blot analysis. SKOV3, HIH-OVCAR3 and TOV-112D cells were resuspended in lysis buffer $(50 \mathrm{mM}$ Tris- $\mathrm{HCl}$, $\mathrm{pH} 7.4 ; 150 \mathrm{mM} \mathrm{NaCl} ; 1 \mathrm{mM}$ EDTA; $1 \%$ NP40; and $0.25 \%$ sodium deoxycholate) containing Complete Protease Inhibitors (Roche Applied Science, Mannheim, Germany). Protein concentration was determined using a DC Protein Assay kit (Bio-Rad Laboratories, Inc., Hercules, CA, USA), according to manufacturer's protocol. A total of $30 \mu \mathrm{g}$ protein was resolved by $10 \%$ SDS-PAGE and transferred onto polyvinylidene fluoride membranes (EMD Millipore, Billerica, MA, USA). Membranes were incubated with the anti-FAK kinase domain (cat. no. GTX50666 GeneTex Inc., Irvine, CA, USA) diluted at 1:1,000 or anti-GAPDH (cat. no. PA1-987 Zymed; Thermo Fisher Scientific, Inc.) diluted at 1:20,000 as a control, at $4^{\circ} \mathrm{C}$ overnight. Membranes were then washed and incubated with the appropriate goat anti-rabbit IgG secondary antibody (horseradish peroxidase-conjugated) diluted at 1:5,000, at room temperature for $40 \mathrm{~min}$ (cat. no. A27036 Zymed; Thermo Fisher Scientific, Inc.). Proteins were detected by chemiluminescence using the Amersham ECL plus Western Blotting Detection System (GE Healthcare Bio-Sciences, Pittsburgh, PA, USA).

RNA extraction and reverse transcription-semi-quantitative polymerase chain reaction ( $R T-q P C R)$ of alternative transcripts. SKOV3, NIH-OVCAR3 and TOV-112D cells were trypsinized, centrifuged and incubated with $1 \mathrm{ml} \mathrm{TRIzol}{ }^{\circledR}$ reagent (Invitrogen; Thermo Fisher Scientific, Inc.) to obtain the RNA, according to manufacturer's protocols. Following centrifugation at $12,000 \mathrm{xg}$ for $10 \mathrm{~min}$ at $4^{\circ} \mathrm{C}$, the aqueous phase was recovered, and $500 \mu \mathrm{l}$ isopropanol was added. Subsequently, an additional centrifugation at $12,000 \mathrm{x}$ g for $10 \mathrm{~min}$ at $4^{\circ} \mathrm{C}$ was performed, and then the pellet was obtained, washed in $70 \%$ ethanol and homogenized. Following centrifugation at 7,500 x g for $5 \mathrm{~min}$ at $4^{\circ} \mathrm{C}$, the pellets were dissolved in $50 \mu \mathrm{H}_{2} \mathrm{O}$. Subsequently, oligoDT cDNA was synthesized with a Promega Reverse Transcription system GoScript ${ }^{\mathrm{TM}}$ (cat. no. A5000; Promega Corporation, Madison, WI, USA). A total of $1 \mu \mathrm{g}$ RNA was incubated at $70^{\circ} \mathrm{C}$ for $5 \mathrm{~min}$ in the presence of $0.5 \mathrm{mg}$ oligoDT, followed by incubation at $4^{\circ} \mathrm{C}$ for $5 \mathrm{~min}$. Finally, Master mix (Recombinant RNasin ${ }^{\circledR}$ Ribonuclease Inhibitor and GoScript ${ }^{\mathrm{TM}}$ Reverse Transcriptase) was added, according to the manufacturer's protocols, and incubated at $25^{\circ} \mathrm{C}$ for $5 \mathrm{~min}$ and then at $42^{\circ} \mathrm{C}$ for $30 \mathrm{~min}, \mathrm{cDNA}$ was stored at $-80^{\circ} \mathrm{C}$ until further use. For amplification of FAK isoforms, the PCR primers reported by Corsi et al (21) were employed (primer M-R2, M-F2, M-F3 and M-F4). These primers were designed to amplify the region between exons 12 and 17. The oligonucleotides used for the amplification of the region comprising exons 12 to 17 were: M-R2, Forward, 5'-AGCGAAAAGCAAGGCATGCGG-3', and M-F2 reverse, 5'-CTGACGCATTGTTAAGGCTTC-3' for the isoforma $\mathrm{FAK}^{28,6}$. For amplification of the remaining isoforms, the $\mathrm{R} 2$ reverse oligonucleotide was used in combination with different forward primers as follows: M-F3 reverse, 5'-TCTCTG TGTCAGAAACAGATGATT-3' for the isoform FAK ${ }^{0}$ without exons 13 and 14; and M-F4 reverse 5'-CTCCTTCTACGG AAACAGATGATT-3' for the isoform FAK ${ }^{8}$ lacking exon 14. For PCR reactions, 1.25 U GoTaq ${ }^{\circledR}$ Flexi DNA Polymerase (cat. no. M8295 Promega Corporation, Madison, WI, USA) were employed under the following conditions: $95^{\circ} \mathrm{C}$ for $2 \mathrm{~min}$, then 30 cycles at $95^{\circ} \mathrm{C}$ for $30 \mathrm{sec}, 57^{\circ} \mathrm{C}$ for $30 \mathrm{sec}$ and $68^{\circ} \mathrm{C}$ for $30 \mathrm{sec}$, followed by a final cycle of $68^{\circ} \mathrm{C}$ for $2 \mathrm{~min}$. Amplification of the ne cycle at 957. For PCR reactions $1.25 \mathrm{U}$ GoTaqs follows: 5'-TCGGGTCAGAAGGATTCCTATG-3', and reverse 5'-GGT CTCAAACATGATCTGGG-3' oligonucleotides under the conditions aforementioned for the FAK isoforms. PCR products were visualized on $1 \%$ agarose gels stained with ethidium bromide. Band intensities were visualized using the Stratagene Eagle Eye II Gel Imaging System and software EagleSight v3.22 (Stratagene, La Jolla, CA, USA).

Statistical analysis. Data are reported as the means \pm standard deviations of three independent experiments. Data from densitometric evaluation were analyzed using one-way analysis of variance test followed by Tukey analysis and Duncan test to compare the level of expression between the experimental groups. In order to compare data from the semi-quantitative 
FAK Kinase Domain
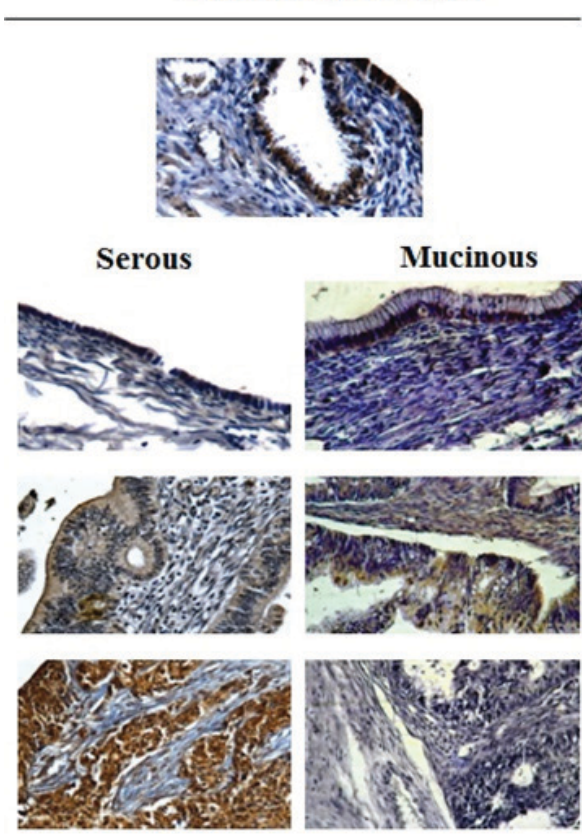

FAK FAT Domain

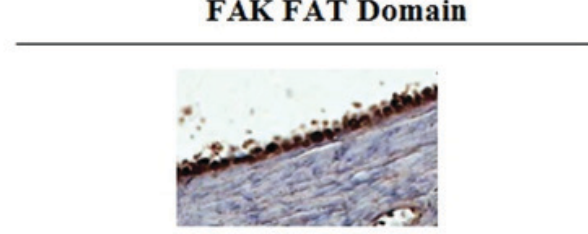

Healthy ovary
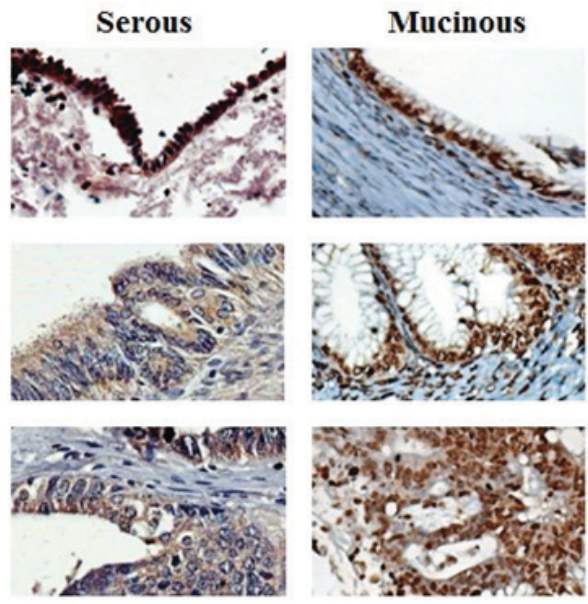

Cystadenoma

\section{Borderline}

tumor

Carcinoma

Figure 1. Expression of FAK in ovarian tumor and healthy ovary samples. Expression of FAK kinase and FAT domains was evaluated with immunohistochemistry in serous and mucinous cystadenoma, borderline tumor and ovarian carcinoma samples. A group of healthy ovary samples was included as negative controls. FAT, focal adhesion targeting; FAK, focal adhesion kinase.

analysis, samples showing low, moderate and high expression from each experimental group were grouped together and considered as the overall positive expression group. Then differences among the experimental groups were evaluated using the Kruskal-Wallis test and Bonferroni correction for pairwise comparisons, Allred et al (26) and Pizon et al (31). $\mathrm{P}<0.05$ was considered to indicate a statistically significant difference.

\section{Results}

Expression of the kinase and FAT domains of FAK in OCa. Expression of FAK kinase and FAT domains was analyzed in healthy ovary, cystadenoma, borderline tumor and ovarian carcinoma tissue samples, which were assembled into a multi-tissue block by immunohistochemistry. The expression of FAK kinase domain was observed in 14 out of 16 samples of healthy ovaries, but immunostaining was low or moderate, with none of the samples exhibiting a high positive expression (Table I). A similar pattern of expression was detected in serous cystadenoma samples, with $56 \%$ of samples exhibiting low or moderate expression and again, with no samples exhibiting a high positive expression. In contrast, all borderline serous tumor samples were positive for expression of the kinase domain, but only one exhibited high positivity. Similarly, all serous carcinoma samples were positive for the expression of the FAK kinase domain, but $74 \%$ of these exhibited high positive expression; additionally, no samples exhibited low positive staining (Table I). The proportion of samples exhibiting expression of the kinase domain in serous cystadenoma, borderline tumor and carcinoma samples was significantly increased, compared with healthy ovary samples $(\mathrm{P}<0.05$; Table I) and a significant difference between borderline tumors and carcinomas was observed $(\mathrm{P}<0.05)$. The expression of the FAK kinase domain was exclusively cytoplasmic in all positive serous samples (Fig. 1). In contrast, none of the mucinous tumor groups exhibited a significantly increased proportion of positive expression of the kinase domain, compared with the healthy ovary samples (Table I). However, it is notable that the staining detected in positive samples was also cytoplasmic (Fig. 1). In agreement with the semi-quantitative analysis, densitometric evaluation demonstrated a significantly increased expression of FAK kinase in borderline tumor and carcinoma samples, compared with healthy ovary samples $(\mathrm{P}<0.05$; Fig. 2$)$. In contrast, no significant difference was detected in mucinous lesions (Fig. 2A).

However, the expression of the FAT domain was observed in $85 \%$ of healthy ovary samples (Fig. 1). Additionally, a high positive expression was detected in 11/16 healthy ovary samples (Table II). There were $88 \%$ of serous cystadenoma samples that exhibited positive expression of the FAT domain, and the difference between this group and the healthy ovary samples was statistically significant $(\mathrm{P}<0.05$; Table II). All serous borderline tumor samples were positive for expression of the FAT domain, exhibiting low-to-high levels of expression (Table II). Similarly, all serous borderline tumor samples analyzed expressed the FAT domain, with $68 \%$ of samples exhibiting moderate-to-high expression (Table II). The proportion of carcinoma samples expressing the FAT domain was significantly increased compared with the serous borderline samples $(\mathrm{P}<0.01$; Table II). For the mucinous tumor samples, it was observed that $68 \%$ of cystadenoma samples expressed low-to-moderate levels of the FAT domain, while all borderline and carcinoma samples demonstrated positive staining, with levels of positivity ranging from low to high (Table II). 
Table I. Expression of focal adhesion kinase kinase domain in healthy ovary, serous and mucinous samples.

\begin{tabular}{|c|c|c|c|c|c|c|}
\hline Histological type & $\begin{array}{l}\text { No. of } \\
\text { cases }\end{array}$ & $\begin{array}{c}\text { Negative } \\
\text { expression (-) }\end{array}$ & $\begin{array}{c}\text { Low } \\
\text { expression (+) }\end{array}$ & $\begin{array}{c}\text { Moderate } \\
\text { expression }(++)\end{array}$ & $\begin{array}{c}\text { High } \\
\text { expression }(+++)\end{array}$ & P-value \\
\hline Healthy ovary samples & 16 & 2 & 6 & 8 & 0 & \\
\hline \multicolumn{7}{|l|}{ Serous tumor types } \\
\hline Cystadenoma & 25 & 11 & 10 & 4 & 0 & $<0.05^{\mathrm{a}}$ \\
\hline Borderline & 25 & 0 & 5 & 19 & 1 & $<0.05^{\mathrm{a}, \mathrm{b}}$ \\
\hline Carcinoma & 50 & 0 & 0 & 13 & 37 & $<0.05^{\mathrm{a}-\mathrm{c}}$ \\
\hline \multicolumn{7}{|l|}{ Mucinous tumor types } \\
\hline Cystadenoma & 25 & 7 & 8 & 10 & 0 & $\mathrm{NS}^{\mathrm{a}}$ \\
\hline Borderline & 14 & 2 & 4 & 6 & 2 & $\mathrm{NS}^{\mathrm{a}, \mathrm{b}}$ \\
\hline Carcinoma & 6 & 1 & 3 & 1 & 1 & $\mathrm{NS}^{\mathrm{a}-\mathrm{c}}$ \\
\hline
\end{tabular}

${ }^{\mathrm{a}}$ vs. normal ovaries; ${ }^{\mathrm{b}} \mathrm{vs}$. cystadenoma; ${ }^{\mathrm{c}}$ vs. borderline. P-values were calculated using the Kruskal-Wallis Test. NS, not significant.
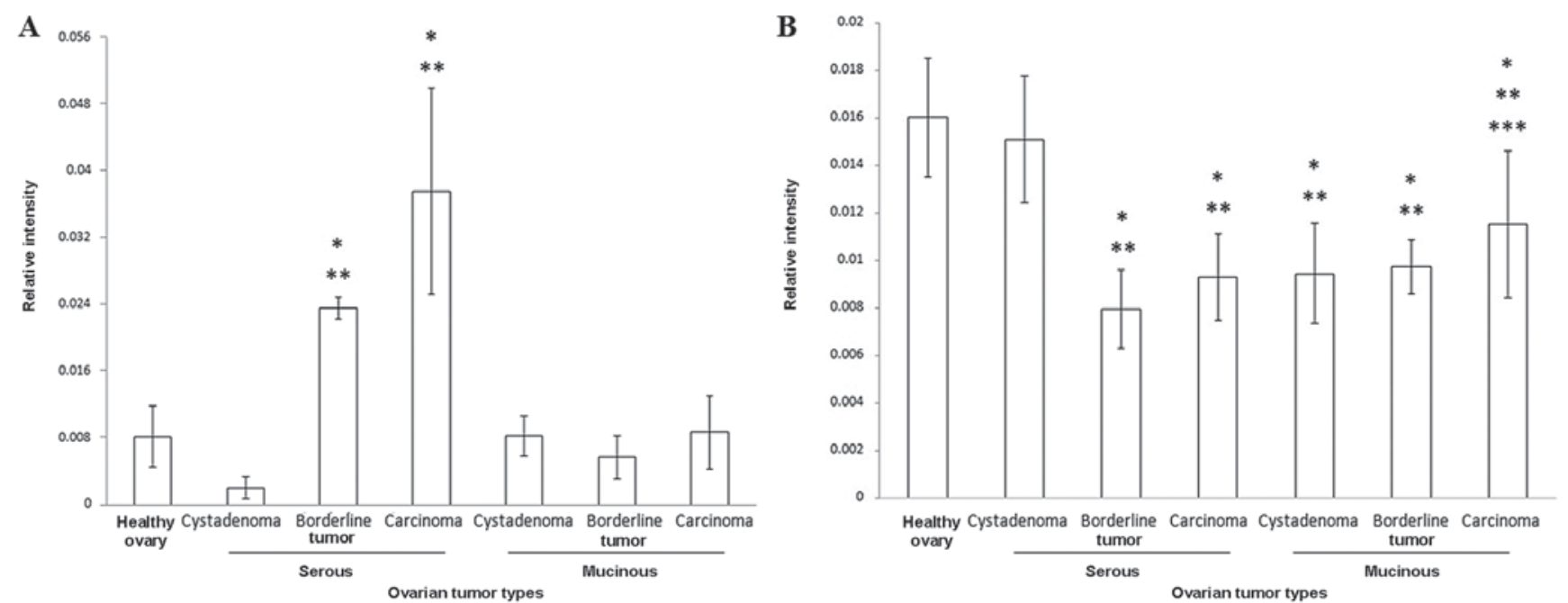

Figure 2. Densitometric analysis of FAK expression in ovarian cancer and healthy ovary samples. Following immunohistochemistry staining, three microphotographs were captured for each serous and mucinous cystadenoma, borderline tumor and ovarian carcinoma samples. Healthy ovary samples were included as negative controls. The samples were analyzed as described in the Materials and methods section. Relative intensity of (A) FAK kinase and (B) FAT domain immunostaining are depicted. Error bars represent the standard deviation of the mean. Differences were calculated using the analysis of variance test, considering a value of $\mathrm{P}<0.05$ as significant difference. ${ }^{*} \mathrm{P}<0.05$, compared with healthy ovary samples; ${ }^{* *} \mathrm{P}<0.05$, compared with cystadenoma samples; ${ }^{* * *} \mathrm{P}<0.05$, compared with borderline serous tumor samples. FAT, focal adhesion targeting; FAK, focal adhesion kinase.

Unlike the kinase domain, the FAT domain exhibited a nuclear and cytoplasmic localization (Fig. 1). Densitometric analysis demonstrated that the expression of FAT was significantly increased in healthy ovary samples, compared with serous and mucinous samples $(\mathrm{P}<0.05$; Fig. 2B).

Expression of FAK kinase and alternative transcripts in $\mathrm{OCa}$ cell lines. The present results demonstrated the expression of FAK in OCa biopsies. In order to evaluate whether FAK is expressed in OCa-derived cell lines, the expression of FAK kinase domain in SKOV3, NIH-OVCAR3 and TOV-112D cells was evaluated with western blotting, with HeLa cells included as a FAK expression control. Incubation with the anti-FAK kinase domain antibody demonstrated the presence of a band of a molecular weight similar to that observed in the positive control. The present results indicated that all three cell lines tested expressed FAK (Fig. 3A). Additionally, to address whether OCa cells expressing different FAK isoforms, the three cell lines were analyzed with RT-qPCR. As depicted in Fig. 3B, three different transcripts were detected. A 300-bp fragment was observed in all cell lines, this transcript corresponds to $\mathrm{FAK}^{28,6}$ isoform. Amplification of the $\mathrm{FAK}^{0}$ isoform was also detected in all cell lines. Finally, the $\mathrm{FAK}^{28}$ fragment was detected in all cell lines. However, SKOV3 cells demonstrated a very weak expression of $\mathrm{FAK}^{0}$ compared with that observed in NIH-OVCAR3 and TOV-112D cells (Fig. 3B).

\section{Discussion}

FAK has been considered an important kinase for the development of tumor types due to it participating in the processes of angiogenesis, proliferation and cell migration (14). Although 
Table II. Expression of focal adhesion kinase focal adhesion targeting domain in healthy ovary, serous and mucinous samples.

\begin{tabular}{|c|c|c|c|c|c|c|}
\hline Histological type & $\begin{array}{l}\text { No. of } \\
\text { cases }\end{array}$ & $\begin{array}{c}\text { Negative } \\
\text { expression (-) }\end{array}$ & $\begin{array}{c}\text { Low } \\
\text { expression (+) }\end{array}$ & $\begin{array}{c}\text { Moderate } \\
\text { expression }(++)\end{array}$ & $\begin{array}{c}\text { High } \\
\text { expression }(+++)\end{array}$ & P-value \\
\hline Healthy ovary samples & 16 & 1 & 2 & 2 & 11 & \\
\hline \multicolumn{7}{|l|}{ Serous tumor types } \\
\hline Cystadenoma & 25 & 3 & 7 & 9 & 6 & $<0.05^{\mathrm{a}}$ \\
\hline Borderline & 25 & 0 & 8 & 14 & 3 & $\begin{array}{c}<0.05^{\mathrm{a}} \\
\mathrm{NS}^{\mathrm{b}}\end{array}$ \\
\hline Carcinoma & 50 & 0 & 10 & 18 & 22 & $\begin{array}{c}\mathrm{NS}^{\mathrm{a}} \\
0.02^{\mathrm{b}} \\
0.01^{\mathrm{c}}\end{array}$ \\
\hline \multicolumn{7}{|l|}{ Mucinous tumor types } \\
\hline Cystadenoma & 25 & 8 & 11 & 6 & 0 & $<0.05^{\mathrm{a}}$ \\
\hline Borderline & 14 & 0 & 3 & 8 & 3 & $\begin{array}{l}\mathrm{NS}^{\mathrm{a}} \\
<0.05^{\mathrm{b}}\end{array}$ \\
\hline Carcinoma & 6 & 0 & 1 & 3 & 2 & $\begin{array}{c}\mathrm{NS}^{\mathrm{a}} \\
<0.05^{\mathrm{b}} \\
\mathrm{NS}^{\mathrm{c}}\end{array}$ \\
\hline
\end{tabular}

${ }^{\mathrm{a}}$ vs. normal ovaries; ${ }^{\mathrm{b}} \mathrm{vs}$. cystadenoma; ${ }^{\mathrm{c}} \mathrm{s}$. borderline. P-values were calculated using the Kruskal-Wallis Test. NS, not significant.

A

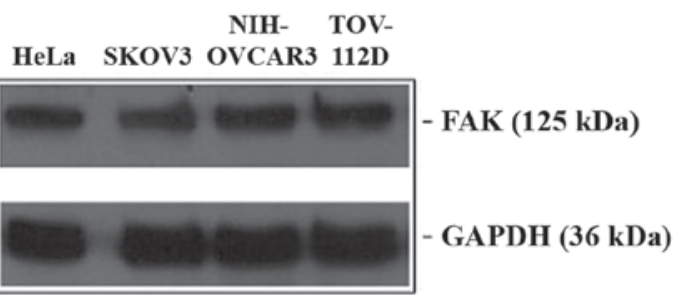

B

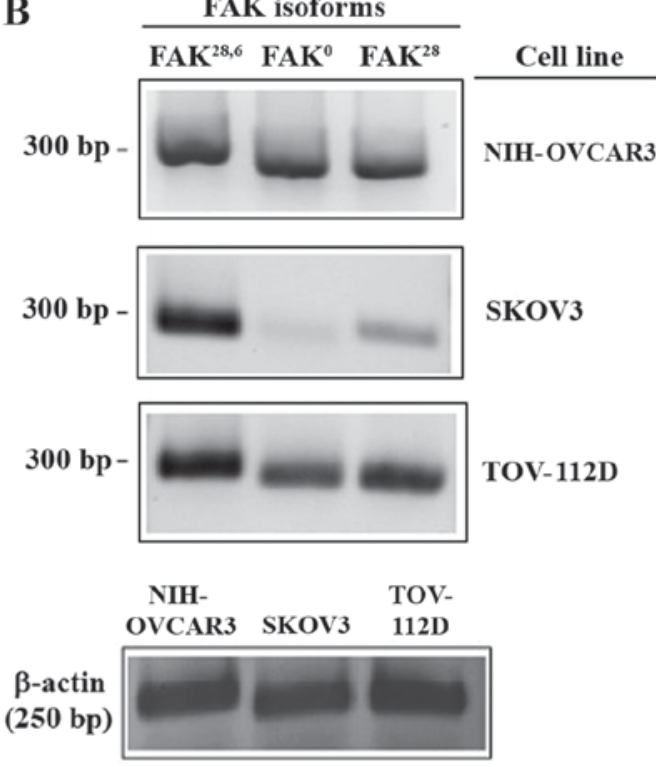

Figure 3. Expression of FAK kinase and alternative transcripts in ovarian cancer cell lines. (A) Expression of FAK was assessed in SKOV3, NIH-OVCAR3 and TOV-112D ovarian cancer-derived cells with western blotting using an anti-FAK kinase domain antibody. HeLa cells were included as a FAK expression control. Detection of GAPDH was used as loading control. (B) Expression of FAK ${ }^{28,6}$, FAK $^{0}$, and FAK ${ }^{28}$ alternative transcripts were investigated in SKOV3, NIH-OVCAR3 and TOV-112D cells with reverse transcription-semi-quantitative polymerase chain reaction. Expression of the $\beta$-actin gene was included as an internal control. Amplified fragments from each cell line were analyzed in separate agarose gels. FAK, focal adhesion kinase.

numerous studies have examined the functions of FAK (15), there are, to the best of our knowledge, limited data evaluating the expression of FAK isoforms in OCa (13).

In the present study, the expression of FAK in serous and mucinous ovarian tumor samples was evaluated with two antibodies (anti-FAK kinase domain and anti-FAK FAT domain). It was observed that the expression of FAK, as demonstrated by positive immunostaining of the kinase domain, was increased in more advanced tumor samples. This observation is consistent with data reported by other research groups, in which FAK increases in advanced stages of serous tumor cases (10,11,22-24). In contrast, when the expression of FAT domain was analyzed, an increased level of expression was observed in healthy ovary samples compared with carcinoma samples. Sood et al (13) determined that the endogenous inhibitor FRNK negatively regulates the phosphorylation of FAK. In the present study, it 
was observed that kinase domain is increased, but FAT domain is reduced, in carcinoma samples; it has previously been demonstrated that the FAK COOH-terminal region, containing the FAT domain, reduces the tyrosine phosphorylation of FAK, inducing apoptosis and loss of adhesion of cancer cells (32). Thus, our observation of a reduction of FAT domain expression in ovarian cancer may be in line with the hypothesis that FAT is negative regulator of FAK activity.

FAK is a cytoplasmic protein, and it is activated and localized in focal adhesions (33). Accordingly, a cytoplasmic expression of FAK kinase domain was observed in serous and mucinous tumor samples; however, the FAT domain was located in the cytoplasm of serous tumor samples and also in the nucleus of mucinous tumor samples. Previous studies demonstrated that nuclear FAK has the ability to modify gene expression (16), providing kinase-independent survival signals to cells; additionally, it is associated with poor prognosis in colorectal cancer (34). The result of the present study indicated that the FRNK isoform is localized in the nucleus of OCa cells.

In addition, the present study determined the expression of alternative FAK transcripts in $\mathrm{OCa}$, which may originate different isoforms of the protein. A limitation of our study was that the evaluation of the FAK isoforms was not carried out simultaneously with that of an internal control. Although this is not standard practice, the expression of $\beta$-actin was demonstrated in samples from the same RNA used for the study of the FAK isoforms, but in an independent reaction. This might cause variability among gels, however, all samples showed the expression of the internal control gene ( $\beta$-actin), and in addition they demonstrated different levels of expression for the three isoforms analyzed. It was observed that all cell lines tested exhibited a high expression of $\mathrm{FAK}^{28,6}$. In an extensive molecular analysis, Corsi et al (21) determined that the expression of FAK 28 and 6 boxes is strongly conserved among vertebrates, indicating an important function for the FAK 28,6 isoform. Notably, it has been proposed that the inclusion of box 6 is associated with increased autophosphorylation of FAK (35), indicating that in $\mathrm{OCa}$, this may produce hyperactivation of multiple downstream signaling pathways. This protein has been proposed as a prognostic marker and as a potential therapeutic target in numerous types of tumor; however, novel evidence of FAK isoforms opens up new questions and perspectives in the treatment of OCa.

\section{Acknowledgements}

The authors would like to thank to Dr. Fabián Jesús Arechavaleta-Velasco and Dr. Laura Díaz-Cueto from the Hospital of Gynecology and Obstetrics No. 4 IMSS, Mexico City, Mexico for their academic support. Additionally, the authors would like to thank Cecilia Aguilar-Zacarías from the department of Molecular Biology and Biotechnology, Institute of Biomedical Research, National University of Mexico, Mexico City, for their technical assistance.

\section{Funding}

The present study was supported by a grant from IMSS (grant no. R-2011-785-066). The present study was performed in partial fulfillment of the requirements of the Programa de
Doctorado en Ciencias Biológicas of Manuel Nolasco-Quiroga at the Universidad Nacional Autónoma de México, with doctoral fellowships from CONACyT (Reg: 211158), COMECyT (Grant no. 15BEPD0036-II), and IMSS (Grant no. 087-2013). The authors would like to thank Posgrado en Ciencias Biológicas, UNAM, Mexico, for academic support.

\section{Availability of data and materials}

The datasets used during the present study are available from the corresponding author upon reasonable request.

\section{Authors' contributions}

MNQ performed the experiments, analyzed and interpreted data, and wrote the manuscript. MRD, JM, RGA, MJLI, PPS, IAC, GVG performed RT-qPCR analysis of cell lines. MNQ, MRD, MJLI, AIC, PPS constructed tissue microarrays, determined FAK on microarrays and evaluated cellular stains. LRZ designed the experiments using cell lines, analyzed and interpreted data. DAA made substantial contributions to the conception of the study. FSG designed the experiments on tissue samples and wrote the manuscript.

\section{Ethics approval and consent to participate}

Ethical approval was awarded collectively by Committee of Ethics of the Century XXI National Medical Center, the General Hospital of Mexico, and the Hospital of Gynecology and Obstetrics No. 4 IMSS (approval no. R-2011-785-066) (Mexico City, Mexico).

\section{Patients consent for publication}

Not applicable.

\section{Competing interests}

The authors declare that they have no competing interests.

\section{References}

1. Coward JI, Middleton K and Murphy F: New perspectives on targeted therapy in ovarian cancer. Int J Womens Health 7: 189-203, 2015.

2. Iyoke CA and Ugwu GO: Burden of gynaecological cancers in developing countries. World J Obstet Gynecol 2: 1-7, 2013.

3. Rauh-Hain JA, Krivak TC, Del Carmen MG and Olawaiye AB: Ovarian cancer screening and early detection in the general population. Rev Obstet Gynecol 4: 15-21, 2011.

4. Goff B: Symptoms associated with ovarian cancer. Clin Obstet Gynecol 55: 36-42, 2012.

5. Kaku T, Ogawa S, Kawano Y, Ohishi Y, Kobayashi H, Hirakawa T and Nakano H: Histological classification of ovarian cancer. Med Electron Microsc 36: 9-17, 2003.

6. Leong HS, Galletta L, Etemadmoghadam D, George J; Australian Ovarian Cancer Study, Köbel M, Ramus SJ and Bowtell D: Efficient molecular subtype classification of high-grade serous ovarian cancer. J Pathol 236: 272-277, 2015.

7. Köbel M, Kalloger SE, Boyd N, McKinney S, Mehl E, Palmer C, Leung S, Bowen NJ, Ionescu DN, Rajput A, et al: Ovarian carcinoma subtypes are different diseases: Implications for biomarker studies. PLoS Med 5: e232, 2008.

8. Canney PA, Moore M, Wilkinson PM and James RD: Ovarian cancer antigen CA125: A prospective clinical assessment of its role as a tumour marker. Br J Cancer 50: 765-769, 1984. 
9. Pepin K, Carmen MD, Brown A and Dizon DS: CA 125 and epithelial ovarian cancer: Role in screening, diagnosis, and surveillance. Am J Hematol Oncol 10: 22-29, 2014.

10. Mitra SK and Schlaepfer DD: Integrin-regulated FAK-Src signaling in normal and cancer cells. Curr Opin Cell Biol 18: 516-523, 2006.

11. Judson PL, He X, Cance WG and Van Le L: Overexpression of focal adhesion kinase, a protein tyrosine kinase, in ovarian carcinoma. Cancer 86: 1551-1556, 1999.

12. Li M, Hong LI, Liao M and Guo G: Expression and clinical significance of focal adhesion kinase and adrenomedullin in epithelial ovarian cancer. Oncol Lett 10: 1003-1007, 2015.

13. Sood AK, Coffin JE, Schneider GB, Fletcher MS, DeYoung BR, Gruman LM, Gershenson DM, Schaller MD and Hendrix MJ: Biological significance of focal adhesion kinase in ovarian cancer: Role in migration and invasion. Am J Pathol 165: 1087-1095, 2004

14. Zhao X and Guan JL: Focal adhesion kinase and its signaling pathways in cell migration and angiogenesis. Adv Drug Deliv Rev 63: 610-615, 2011.

15. Hall JE, Fu W and Schaller MD: Focal adhesion kinase : Exploring Fak structure to gain insight into function. Int Rev Cell Mol Biol 288: 185-225, 2011.

16. Lim ST: Nuclear FAK: A new mode of gene regulation from cellular adhesions. Mol Cells 36: 1-6, 2013.

17. Dixon RD, Chen Y, Ding F, Khare SD, Prutzman KC, Schaller MD, Campbell SL and Dokholyan NV: New insights into FAK signaling and localization based on detection of a FAT domain folding intermediate. Structure 12: 2161-2171, 2004.

18. Schaller MD, Borgman CA and Parsons JT: Autonomous expression of a noncatalytic domain of the focal adhesion-associated protein tyrosine kinase pp125FAK. Mol Cell Biol 13: 785-791, 1993

19. Toutant M, Costa A, Studler J, Kadaré G, Carnaud M and Girault JA: Alternative splicing controls the mechanisms of FAK autophosphorylation. Mol Cell Biol 22: 7731-7743, 2002.

20. Contestabile A, Bonanomi D, Burgaya F, Girault JA and Valtorta F: Localization of focal adhesion kinase isoforms in cells of the central nervous system. Int J Dev Neurosci 21: 83-93, 2003.

21. Corsi JM, Rouer E, Girault JA and Enslen H: Organization and post-transcriptional processing of focal adhesion kinase gene. BMC Genomics 7: 198, 2006.

22. Despeaux M, Chicanne G, Rouer E, De Toni-Costes F, Bertrand J, Mansat-De Mas V, Vergnolle N, Eaves C, Payrastre B, Girault JA and Racaud-Sultan C: Focal adhesion kinase splice variants maintain primitive acute myeloid leukemia cells through altered Wnt signaling. Stem Cells 30: 1597-1610, 2012.

23. Grisaru-Granovsky S, Salah Z, Maoz M, Pruss D, Beller U and Bar-Shavit R: Differential expression of protease activated receptor 1 (Par1) and pY397FAK in benign and malignant human ovarian tissue samples. Int J Cancer 113: 372-378, 2005.

24. Lark AL, Livasy CA, Dressler L, Moore DT, Millikan RC, Geradts J, Iacocca M, Cowan D, Little D, Craven RJ and Cance W: High focal adhesion kinase expression in invasive breast carcinomas is associated with an aggressive phenotype. Mod Pathol 18: 1289-1294, 2005.
25. Hidalgo A, Piña P, Guerrero G, Lazos M and Salcedo M: A simple method for the construction of small format tissue arrays. J Clin Pathol 56: 144-146, 2003.

26. Allred DC, Harvey JM, Berardo M and Clark GM: Prognostic and predictive factors in breast cancer by immunohistochemical analysis. Mod Pathol 11: 155-168, 1998.

27. Fogh J: Human tumor cells in vitro. Plenum Press New York: pp115-141, 1975

28. Hamilton TC, Young RC, Mckoy WM, Grotzinger KR, Green JA, Chu EW, Whang-Peng J, Rogan AM, Green WR and Ozols RF: Characterization of a human ovarian carcinoma cell line (NIH:OVCAR-3) with androgen and estrogen receptors. Cancer Res 43: 5379-5389, 1983.

29. Provencher DM, Lounis H, Champoux L, Tétrault M, Manderson EN, Wang JC, Eydoux P, Savoie R, Tonin PN and Mes-Masson AM: Characterization of four novel epithelial ovarian cancer cell lines. In Vitro Cell Dev Biol Anim 36: $357-361,2000$.

30. McCormack SJ, Brazinski SE, Moore JL Jr, Werness BA and Goldstein DJ: Activation of the focal adhesion kinase signal transduction pathway in cervical carcinoma cell lines and human genital epithelial cells immortalized with human papillomavirus type 18. Oncogene 15: 265-274, 1997.

31. Pizon M, Schott DS, Pachmann U and Pachmann K: B7-H3 on circulating epithelial tumor cells correlates with the proliferation marker, Ki-67, and may be associated with the aggressiveness of tumors in breast cancer patients. Int J Oncol 53: 2289-2299, 2018.

32. Xu LH, Yang X, Craven RJ and Cance WG: The COOH-terminal domain of the focal adhesion kinase induces loss of adhesion and cell death in human tumor cells. Cell Growth Differ 9: 999-1005, 1998.

33. Parsons JT: Focal adhesion kinase: The first ten years. J Cell Sci 116: 1409-1416, 2003.

34. Albasri A, Fadhil W, Scholefield JH, Durrant LG and Ilyas M: Nuclear expression of phosphorylated focal adhesion kinase is associated with poor prognosis in human colorectal cancer. Anticancer Res 34: 3969-3974, 2014.

35. Toutant M, Studler JM, Burgaya F, Costa A, Ezan P, Gelman M and Girault JA: Autophosphorylation of Tyr397 and its phosphorylation by Src-family kinases are altered in focal-adhesion-kinase neuronal isoforms. Biochem J 348: 119-128, 2000.

This work is licensed under a Creative Commons Attribution-NonCommercial-NoDerivatives 4.0 International (CC BY-NC-ND 4.0) License. 